University of Wollongong

Research Online

Faculty of Science - Papers (Archive)

Faculty of Science, Medicine and Health

$1-1-2005$

\title{
The effect of local plant density on pollinator behavior and the breeding system of Persoonia bargoensis (Proteaceae)
}

\author{
David J. Ayre \\ University of Wollongong, david_ayre@uow.edu.au \\ David Field \\ dlf02@uow.edu.au \\ Robert J. Whelan \\ University of Wollongong, rob@uow.edu.au
}

Follow this and additional works at: https://ro.uow.edu.au/scipapers

\section{Recommended Citation}

Ayre, David J.; Field, David; and Whelan, Robert J.: The effect of local plant density on pollinator behavior and the breeding system of Persoonia bargoensis (Proteaceae) 2005, 969-977.

https://ro.uow.edu.au/scipapers/1165 


\title{
The effect of local plant density on pollinator behavior and the breeding system of Persoonia bargoensis (Proteaceae)
}

\author{
Abstract \\ Local plant density can vary dramatically within populations and may modify both the quantity and \\ effectiveness of pollinator activity and thus the reproductive output of plants. We tested the effects of \\ local plant density and plant size on pollinator activity on the endangered plant Persoonia bargoensis in \\ two remnant populations in Australia. Pollinator visitation was weakly but positively correlated with local \\ plant density in both populations ( $R 21 / 40: 25, \mathrm{P}<0: 001 ; \mathrm{R} 2 \frac{114}{4}$ 0:06, $\mathrm{P} \frac{1 / 4}{4}$ 0:024) and with plant size in one \\ population (R2 1/4 0:24, P<0:001). Within-plant movement of fluorescent dyes (added to anthers as a \\ pollen mimic) was inversely related to local flower density (R2 11/4 0:689, $P$ 1/4 0:041). To assess self- \\ compatibility in P. bargoensis, we measured the presence of pollen tubes in flowers that were hand \\ pollinated with self or outcross pollen, which indicated that plants were self-compatible with a weak \\ preference for outcross pollen. The autogamy (mechanical self-pollination) treatment indicated that \\ pollinators are required for pollination. The open treatment showed low and highly variable pollination \\ rates for a rare species (only $20 \%$ of 120 had pollen tubes), suggesting that plants receive variable \\ pollinator service. Reliance on pollinators and a preference for outcross pollen implies that the observed \\ pollinator behavior would reduce the reproductive output of P. bargoensis at low local densities.

\section{Keywords} \\ effect, local, plant, density, pollinator, behavior, breeding, system, Persoonia, bargoensis, Proteaceae

\section{Publication Details} \\ Field, D., Ayre, D. J. \& Whelan, R. J. (2005). The effect of local plant density on pollinator behavior and the \\ breeding system of Persoonia bargoensis (Proteaceae). International Journal of Plant Sciences, 6 \\ 969-977. Copyright 2005 University of Chicago Press.
}


Int. J. Plant Sci. 166(6):969-977. 2005.

(c) 2005 by The University of Chicago. All rights reserved.

$1058-5893 / 2005 / 16606-0008 \$ 15.00$

\title{
THE EFFECT OF LOCAL PLANT DENSITY ON POLLINATOR BEHAVIOR AND THE BREEDING SYSTEM OF PERSOONIA BARGOENSIS (PROTEACEAE)
}

\author{
David L. Field, ${ }^{1}$ David J. Ayre, and Robert J. Whelan \\ Institute for Conservation Biology, School of Biological Sciences, University of Wollongong, New South Wales 2522, Australia
}

\begin{abstract}
Local plant density can vary dramatically within populations and may modify both the quantity and effectiveness of pollinator activity and thus the reproductive output of plants. We tested the effects of local plant density and plant size on pollinator activity on the endangered plant Persoonia bargoensis in two remnant populations in Australia. Pollinator visitation was weakly but positively correlated with local plant density in both populations $\left(R^{2}=0.25, P<0.001 ; R^{2}=0.06, P=0.024\right)$ and with plant size in one population $\left(R^{2}=0.24, P<0.001\right)$. Within-plant movement of fluorescent dyes (added to anthers as a pollen mimic) was inversely related to local flower density $\left(R^{2}=0.689, P=0.041\right)$. To assess self-compatibility in $P$. bargoensis, we measured the presence of pollen tubes in flowers that were hand pollinated with self or outcross pollen, which indicated that plants were self-compatible with a weak preference for outcross pollen. The autogamy (mechanical self-pollination) treatment indicated that pollinators are required for pollination. The open treatment showed low and highly variable pollination rates for a rare species (only $20 \%$ of 120 had pollen tubes), suggesting that plants receive variable pollinator service. Reliance on pollinators and a preference for outcross pollen implies that the observed pollinator behavior would reduce the reproductive output of $P$. bargoensis at low local densities.
\end{abstract}

Keywords: pollination, pollinator behavior, fragmentation, plant density, pollen tubes.

\section{Introduction}

Habitat fragmentation and destruction can change the spatial distribution of plants, with potentially severe consequences to ecologically important processes such as plant-pollinator interactions (Bosch and Waser 1999; Goverde et al. 2002). A major contributor is the effect that decreasing local plant density (number of individuals per local area or spacing between individuals) can have on pollinator behavior, reducing pollinator abundance (Kunin 1997b) and altering movement patterns between plants (Karron et al. 1995; Cresswell 1997). These changes to pollinator behavior may result in depressed reproductive success and offspring fitness through pollen limitation (references in Kunin 1997b) and increased geitonogamous and biparental inbreeding (de Jong et al. 1993; Karron et al. 1995).

Pollinator behavior is expected to vary with respect to the distribution of individual flowers and plants because pollinators visit flowers while foraging for resources, and they tend to forage in an economically efficient manner (Heinrich 1979; Pyke 1984). Within sparse populations, pollinator visitation per plant is likely to be reduced since the plants would be less attractive as a resource to pollinators because of the greater energy required and longer time spent to move greater distances between flowers (Zimmerman 1981). Furthermore, pollinators that are within sparse populations may make more visits within plants because of the greater distances needed to

\footnotetext{
${ }^{1}$ E-mail dlf02@uow.edu.au.
}

Manuscript received March 2005; revised manuscript received July 2005. reach the nearest neighbor (Karron et al. 1995; Mustajarvi et al. 2001).

Previous work has examined how pollinator behavior is influenced by a single attribute or a combination of attributes such as overall patch size (Jennersten and Nilsson 1993), plant size (Thomson 1988), fragmentation (Goverde et al. 2002), and local population size (Sih and Baltus 1987; Kunin 1997b; Mustajarvi et al. 2001). While many of these attributes have effects on pollinators, local variation in plant density has been found to have the most consistent and strongest influence on pollinator abundance and movements (review Kunin 1997a).

Previous research is largely from studies of fine-scale experimental arrays because they allow control of confounding variables (e.g., population size, density, plant size, geometry) found in natural populations (Karron et al. 1995). Pollinator abundance and movements have been estimated mostly through direct observations (Klinkhamer et al. 1989; Kunin 1993, 1997a, 1997b; Karron et al. 1995) or by using fluorescent dyes, which have been found to be a good analog of pollen transfer (Waser and Price 1982; Cresswell et al. 1995). With most research focusing on experimental arrays of small annual and herbaceous species, there has been little empirical study to indicate whether local density effects translate to natural populations, especially in larger plant forms. This is of particular interest to conservation biology because rare species often occur in small and sparse populations that may be at increased risk of local extinction if pollinator behavior follows patterns in natural populations that are similar to experimental arrays.

The extent to which altered pollinator activity will affect plant reproductive success and offspring fitness may initially 
depend on the breeding system of the plant (Van Treuren et al. 1993; Richardson et al. 2000). For a self-compatible species, reduced pollinator visitation and increased withinplant movements may not reduce seed set; however, offspring may suffer from reduced fitness because of inbreeding depression (Charlesworth and Charlesworth 1987). For a selfincompatible species, the reproductive success will be limited by both the reduction in pollinator visits (pollen limitation) and increased within-plant movements (self pollen) (Kunin 1997b). Therefore, understanding the likely impact of local plant density on pollinators clearly requires that the breeding system (determined by self-incompatibility level) can be estimated.

We examined natural variation in local plant density and its effects on pollinator abundance and pollinator movement in a long-lived perennial shrub species, the endangered Persoonia bargoensis. This species was suitable for this study because populations exhibited considerable variation in local density. Since the breeding system of this endangered plant was previously unknown, this study was a good opportunity to explore it. Specifically, we matched direct observations of pollinator abundance with estimates of local plant density and experimentally assessed pollinator movements within and among plants through tests of the transfer of fluorescentlabeled pollen. In order to predict the consequences for this plant of different patterns of pollinator behavior, we used hand pollinations, pollinator exclusion, and assessment of following pollen tube development to determine the level of selfincompatibility in P. bargoensis.

\section{Methods}

\section{Study Species}

Persoonia bargoensis (Proteaceae) is listed as endangered in the state of New South Wales, Australia (Threatened Species Conservation Act 1995). It is an erect to low spreading tree, up to $3 \mathrm{~m}$ tall, confined to five small populations located in the tablelands southwest of Sydney that range in size from 50 to 300 individuals, and populations occur in woodland and dry sclerophyll forest on sandstone and laterite soils (Weston and Johnson 1991). Persoonia bargoensis flowers are yellow and arranged randomly in the axils of leaves with typical floral characteristics of some of the more common species such as Persoonia pinifolia (see Bernhardt and Weston 1996). The flowers are hermaphroditic, with each flower having four tepals (7-10 mm long), four stamens, and a pistil containing two ovules. The anthers dehisce prior to anthesis, and $5 \mathrm{~d}$ later the tepals and anthers fall off, leaving the gynoecium exposed; however, it is not known whether the flowers are protandrous. Each fruit reaches maturity $7-8$ mo after flowering, producing a single seed. The $P$. bargoensis peak flowering period is from December to March, with each plant remaining in bloom for 10-18 d when more than 100 flowers may be open on a single plant at a given time (D. L. Field, personal observation). Like other Persoonia species, bees seem to be the primary pollinator (Bernhardt and Weston 1996) and were attracted to the flowers, since they were observed foraging flowers for nectar and pollen.

\section{Study Areas and Population Characteristics}

Two study populations were selected on the southern tablelands about $70 \mathrm{~km}$ southeast of Sydney. Population 1 (Charlies Point Road, $\left.34^{\circ} 15^{\prime} 30^{\prime \prime} \mathrm{S}, 150^{\circ} 35^{\prime} 55^{\prime \prime} \mathrm{E}\right)$ contained 93 adult plants. Population 2 (Picton Road, $34^{\circ} 15^{\prime} 00^{\prime \prime} \mathrm{S}, 150^{\circ} 44^{\prime} 00^{\prime \prime} \mathrm{E}$ ) contained 149 adult plants and was approximately $25 \mathrm{~km}$ from population 1.

At each population, we mapped the location of each reproductive P. bargoensis plant and assessed the density of flowering individuals. For each flowering plant, two attributes were measured: (1) local population density, defined as the number of flowering $P$. bargoensis individuals within a $30-\mathrm{m}$ radius; and (2) plant volume, which was calculated from the height (ground to top of canopy), width, and breadth measurements of the plant, assuming an elliptical shape $(4 / 3 \times \pi \times$ height $\times$ width $\times$ breadth). Mean differences in population characteristics between populations were examined with an unpaired $t$-test (assuming unequal variances).

\section{Pollinator Abundance}

To estimate the number of pollinators foraging on individual plants, 54 flowering plants from population 1 and 56 plants from population 2 were randomly selected for observations. Plants were observed during two 90-min surveys in late morning (1100-1230 hours) and midafternoon (14001530 hours). This was repeated twice a week for 3 wk (12 surveys total) during peak flowering, which was in late December 2000 and January 2001 at population 1 and from January to February 2001 at population 2. Pollinator observations were limited to days with similar warm weather conditions $\left(>22^{\circ} \mathrm{C}\right)$ to maximize the likelihood of similar pollinator activity. Within each 90 -min survey, we randomly selected 18 of the plants and observed each for 5 min, during which time we recorded pollinator species and their abundance. Bee pollinator species visiting $P$. bargoensis were grouped into either Australian native bee types (Leioproctus Colletidae, Lasioglossum/Homalictus Halictidae, Exoneura Apidae), identified by their size $(7-10 \mathrm{~mm})$ and black abdomen, or the introduced honeybee Apis mellifera (Apidae), identified by their larger size $(12-20 \mathrm{~mm})$ and yellow and black abdomen. By the end of the survey, each of the plants (54 from population 1; 56 from population 2) had been observed three to six times.

Pollinator abundance is expressed as mean number of pollinator visits per plant per $5 \mathrm{~min}$. We could not express our observations per 100 flowering units because of the large size of $P$. bargoensis plants and the number of individuals (each has 200-500 flowers). A weighted least squares linear regression (Zar 1984) was used to examine the relationship between the mean number of pollinators that visited a plant, plant density, and plant size. This analysis was chosen because it takes into account variation in sample sizes for each data point. Mean differences in population characteristics between populations were examined with an unpaired $t$-test (assuming unequal variances). A Mantel test (MANTEL procedure, GENSTAT version 7) was used to assess the extent of spatial autocorrelation among individuals that could be violating the assumption of independence between individual plants. Mantel tests using sums of squares and product-moment 
correlations were used to compare the similarity between matrix of geographic distance between all individuals with Euclidean distances matrices of pollinator abundance, local population density, and plant size. The significance of the associations was tested with a permutation test of 1000 .

\section{Pollinator Foraging Patterns}

We labeled pollen with fluorescent dye in order to estimate pollinator movement among and within individual plants across a range of local densities. This experiment was conducted within population 2 under warm weather conditions $\left(25^{\circ} \mathrm{C}+\right)$ in late February 2001. Within each of six locations, we chose a single mature $P$. bargoensis plant with at least 100 open flowers per source for the dye. Sites were arbitrarily chosen so that there were three replicates for low density and three for high. Low density was defined as two to four $P$. bargoensis within a $15-\mathrm{m}$ radius of a source plant, and high density was defined as more than nine plants within a $15-\mathrm{m}$ radius. The location size of a $15-\mathrm{m}$ radius was chosen because it matched the scale at which variation in flower density was obvious and it was a realistic sample size to survey. To minimize the possibility of contamination of the dye between different source plants, we used local flowering environments that were at least $40 \mathrm{~m}$ apart, because a previous study on a related species, Persoonia mollis, found the mean distance that pollinators moved between plants was $33 \mathrm{~m}$ (Krauss 2000).

During early morning (0800-0900 hours), we applied Rad Glo powder (for details, see Thomson 1981; Fenster 1991; Eguiarte et al. 1993) to the anthers of 40-50 fresh flowers located on a single branch of each source plant. Powder was lightly dabbed onto the anthers using the end of a toothpick. Then we recorded the total number of flowers open on the source plant and each of the $P$. bargoensis within a $15-\mathrm{m}$ radius. That night (after 2100 hours), we scanned each P. bargoensis within the six sites with a portable ultraviolet lamp to record the number of flowers with fluorescing dye particles on stigmas.

The effectiveness of within-plant pollination was expressed as the number of flowers visited (i.e., dye on stigma) as a proportion of the total set of flowers available on the source plant (excluding the 50 flowers dyed for the source). The effectiveness of among-plant pollination was expressed as the ratio of the total number of visited flowers on all of the plants within the $15-\mathrm{m}$ radius of the source pollen to the total flowers available (excluding the source plant). Density was measured as the total number of flowers within $15 \mathrm{~m}$ from all individual plants. We tested whether there was a relationship between density and (i) within-plant pollination effectiveness, (ii) among-plant pollination, and (iii) number of among-plant pollination events as a percentage of total number pollinations within $15 \mathrm{~m}$. The significance of each relationship was analyzed using separate linear regression analysis. Replicated experiments at population 1 were not conducted because continuous wet weather prohibited dye deposition and pollinator activity.

\section{Experimental Pollinations}

To assess the level of self-incompatibility, we conducted experimental hand pollinations during peak flowering. From each of the two populations, we selected five mature plants of approximately equal size and with at least 200 unopened flowers. On each of these plants, we chose four branches with at least 25 unopened flowers. One branch was randomly assigned to each of the following four treatments; (1) outcross pollination: bagged, flowers were emasculated (to avoid self pollen deposition) and hand pollinated with mixed pollen from four different plants at least $15 \mathrm{~m}$ away (outcross donor branches were also bagged); (2) self-pollination: bagged, flowers were hand pollinated with pollen from flowers on the same branch and/or from the same plant; (3) autogamy (mechanical self-pollination): bagged, flowers were not hand pollinated to assess the ability to self-fertilize in the absence of pollinators; (4) open: unbagged, flowers were not hand pollinated to assess the ability of insect pollinators to pollinate flowers.

Each branch was first prepared by removing all open flowers so that only unopened flowers remained, since it was certain that these had not received any pollinator visits. Then we bagged branches (where appropriate) with $2 \times 2-\mathrm{mm}$ fiberglass mesh bags to prevent pollinator visits (Goldingay et al. 1991). Two days later, 15 flowers/treatment were tagged and pollinated (where appropriate). Hand pollinations first required the collection of the appropriate pollen, which was removed from flowers by excising the anthers with scissors and placing them in sterile vials. Self pollen was gathered from excess flowers within the bagged branches, and outcross pollen was collected from flowers on the bagged branches of three donor plants at least $15 \mathrm{~m}$ distant. Pollen was applied to receptive flowers within $4 \mathrm{~h}$ of collecting the pollen to ensure its viability. Pollen was lightly dabbed onto the stigma using a pollen applicator, which was made from a toothpick cut off at one end to create a rough surface to which pollen adhered.

Gynoecia were removed from each treatment $11 \mathrm{~d}$ after pollination. This time period has been shown to be ample time for pollen tube growth and possible ovule penetration in other Persoonia species (Krauss 1994). Gynoecia were stained for pollen tubes (Martin 1959), with the following modifications. Gynoecia were softened in $0.1 \mathrm{M}$ sodium hydroxide for $15 \mathrm{~h}$ prior to staining in decolorized aniline blue. Second, the gynoecia were bisected longitudinally and the opaque style wall spread apart prior to viewing under a fluorescent microscope. Styles were scored for (i) the presence/ absence of pollen tubes, (ii) the distance that pollen tubes had grown along the style (as one-fourth, one-half, three-fourths), (iii) whether pollen tubes were fragmented or continuous, and (iv) penetration of the ovule by pollen tubes. Flowers could not be followed through to seed set because P. bargoensis takes at least 10 mo to set seed, which was beyond the time frame available for this research project.

Since the data were nonnormal, because of the large proportion of flowers that displayed no pollen tube development, we used a nonparametric Kruskal-Wallis test with tied ranks to first test for heterogeneity of pollination success among pollination treatments. A Tukey multiple comparisons test was then used to determine which treatments were significantly different. Fisher's exact test was also used to examine the difference in presence and absence of fragmented pollen tubes between the outcross and self treatments. 


\section{Results}

\section{Population Characteristics}

The mean local flowering environment around each plant was significantly less dense at population 1 (mean $\pm \mathrm{SE}=$ $8.4 \pm 0.51$ ) compared with population 2 (mean $\pm \mathrm{SE}=$ $24.19 \pm 1.18)(t=12.1, P<0.05)$. At population 1 , the local density ranged from 0 to 20 , with half of the plants $(50 \%$ of 93) having $<10$ individuals within $30 \mathrm{~m}$ (fig. 1A). In contrast, the local density at population 2 had a wider range, from 0 to 50 plants within $30 \mathrm{~m}$; however, only $18 \%$ of plants had $<10$ individuals within $30 \mathrm{~m}$ (fig. $1 B$ ). Plants at population 1 were larger (mean $\pm \mathrm{SE}=23.1 \mathrm{~m}^{3} \pm 2.6$ ) than those at population 2 (mean $\pm \mathrm{SE}=14.9 \mathrm{~m}^{3} \pm 0.96$ ) $(t=3.4, P<0.05)$. A Mantel test showed no spatial autocorrelation with the distance between individual plants and local population density (population 1: $P=0.99$; population 2: $P=0.99$ ) or plant size (population 1: $P=0.25$; population 2: $P=0.39$ ).

\section{Pollinator Abundance and Plant Density}

We observed both the introduced honeybee Apis mellifera (Apidae) and native bees Leioproctus (Colletidae) visiting the flowers of Persoonia bargoensis. The honeybees were by far the most common visitor at each population $197 \%$ and $94 \%$ of 446 and 137 pollinator visits at populations 1 and 2, respectively). Mean pollinator visitation was higher in population $1(t=6.1, P<0.05)$, where it ranged from 0 to 8.3 per plant per 5 min compared with 0 to 3.5 in population 2 . The honeybee was also observed visiting flowers of Eucalyptus and Banksia species at population 2.

Within both populations, we found that pollinator visitation was weakly but positively correlated with local plant density (population 1: $R^{2}=0.25, P<0.001$; population 2: $R^{2}=0.06, P=0.024$ ) (fig. $2 A, 2 B$ ). The frequency of pollinator visits was also weakly but positively correlated with plant size at population $1\left(R^{2}=0.23, P<0.001\right)$; however, there was no relationship at population $2(P>0.05)$ (fig. $2 C$, 2D). A Mantel test showed no spatial autocorrelation with the distance between individual plants and mean pollinator visitation per plant at either population (population 1: $P=0.31$; population 2: $P=0.86)$.

\section{Pollinator Foraging Patterns}

Flower visitors moved fluorescent dye to flowers both within the source plant and to other plants within the local environment. For the within-plant dye movements, the proportion of flowers receiving dye ranged from $7 \%$ in the highest density environment ( 720 flowers) to $22 \%$ in the lowest local density environment (130 flowers), and this proportion decreased significantly as the number of flowers within the local environment increased $\left(R^{2}=0.689, P=0.041\right)$ (fig. $3 A$ ). There was, however, no significant linear relationship between the number of flowers within the local environment and the mean proportion of among-plant dye movements $\left(R^{2}=0.031, P=0.26\right)$ (fig. $3 B$ ) or the percentage of amongplant dye movements relative to the total number of dyed flowers $\left(R^{2}=0.012, P=0.86\right)$ (fig. $\left.3 C\right)$.

\section{A. Population 1}

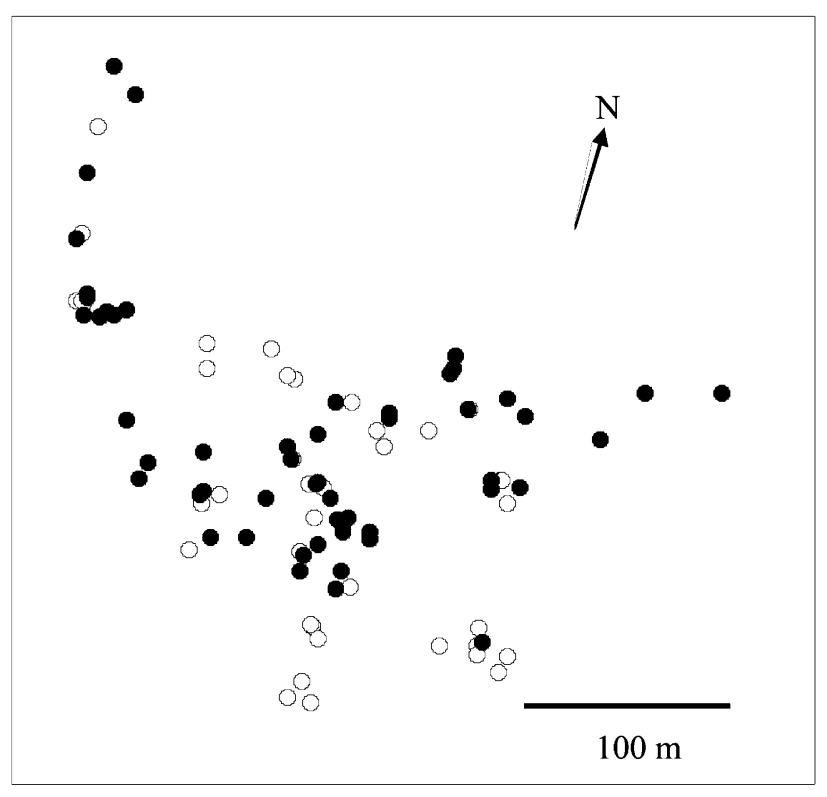

\section{B. Population 2}

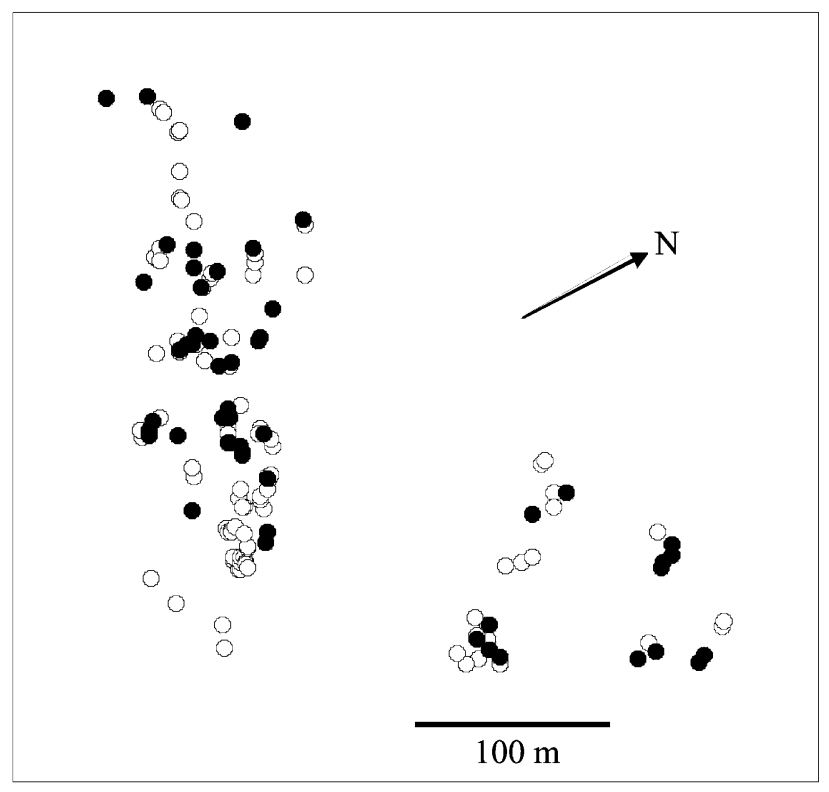

Fig. 1 Distribution of flowering Persoonia bargoensis at $(A)$ population 1, Charlies Point Road, Bargo, and $(B)$ population 2, Picton Road, New South Wales. Solid circles represent individuals selected for pollinator observations; open circles are individuals not sampled but included in density measures.

\section{Experimental Pollinations}

Levels of successful pollination as measured by the presence/ absence of pollen tubes were low, with tubes observed in only $15 \%$ of flowers (71 of 470 ). Of all pollen tubes across all treatments, only $6 \%$ (4 of 71 ) had penetrated the ovule. 


\section{A. Population 1}

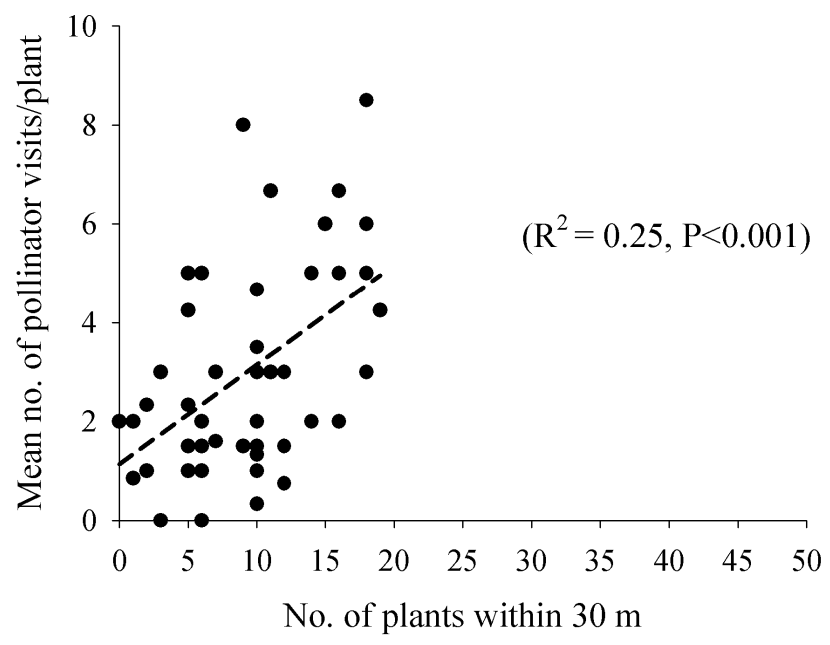

\section{Population 1}

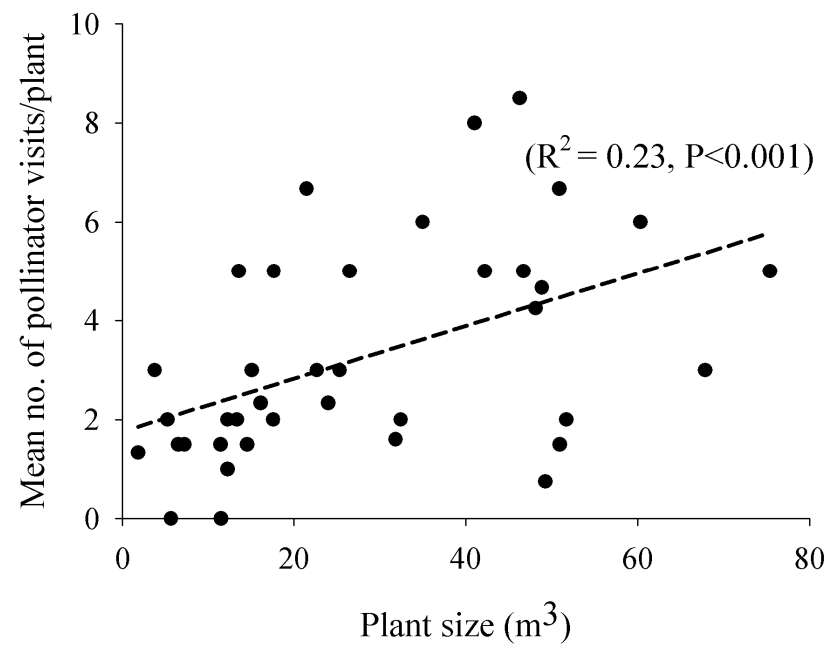

B. Population 2

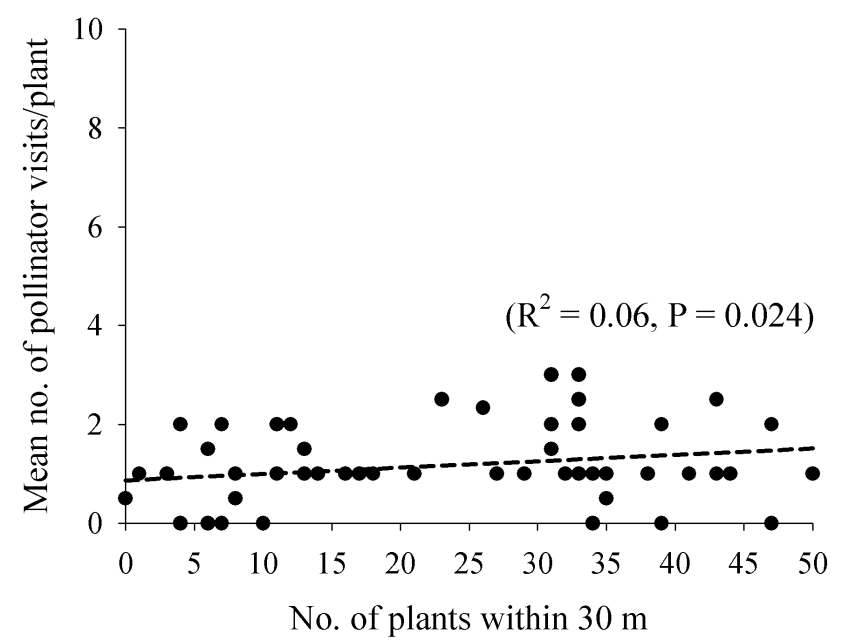

D. Population 2

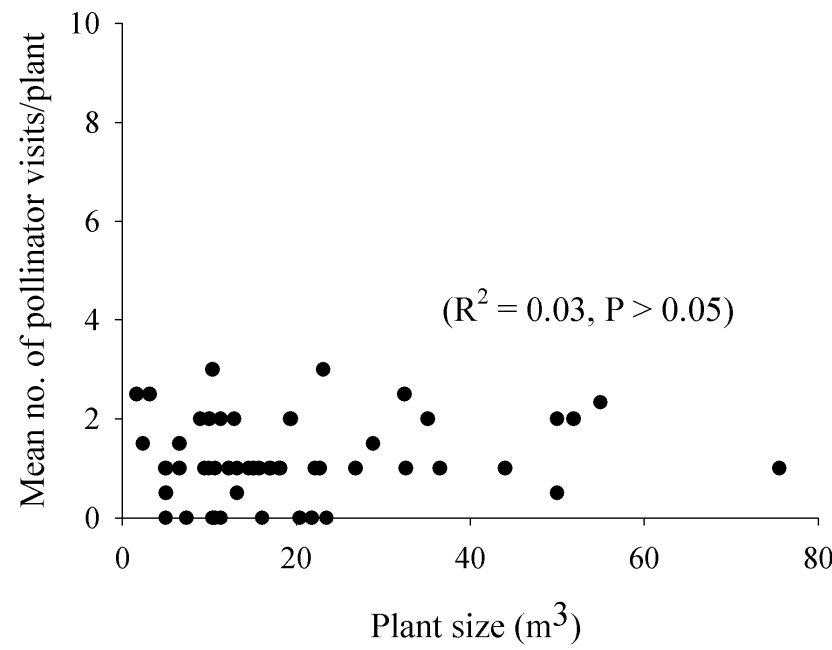

Fig. 2 Weighted linear regression of the mean number of pollinators (of all species) visiting an individual plant against the number of flowering plants within the local environment (30-m radius) at populations 1 and $2(A, B)$ and against plant size (measured by volume $=4 / 3 \times \pi \times$ height $\times$ width $\times$ breadth) at populations 1 and $2(C, D)$.

Therefore, successful pollination was inferred from the presence of a minimum of one pollen tube present in the style, with the absence of any pollen tubes being an unsuccessful pollination. The outcross treatment performed consistently well in both populations, with the presence of pollen tubes ranging from $8 \%$ to $58 \%(n=12$ flowers per treatment), and it was the only treatment in which pollen tubes were present in flowers for every sampled plant (fig. 4). In comparison, pollen tube presence in the self treatment ranged from $0 \%$ to $17 \%$ (with one outlier removed). One outlier plant had an unusually high percentage of pollen tubes for the self treatment (7 of 12) compared with the same treatment on other trees and was left out of the following statistical analysis (see fig. 4B).

The outcross treatment produced a significantly higher percentage of pollen tubes than the self treatment at population
2 (Tukey test, $q=2.8, \mathrm{df}=3, P<0.05)(P>0.05$ if outlier included), but there was no significant difference at population $1(q=2.0, P>0.05)$. Furthermore, we found no significant difference at either population between the self and either the mechanical autogamy (population $1: q=1.55$, $P>0.05$; population $2: q=2.0, P>0.05)$ or the open treatments (population 1: $q=1.52, P>0.05$; population $2: q=$ $1.9, P>0.05$ ) (fig. 4).

In both populations, the flowers from the mechanical autogamy treatment had consistently low numbers of pollen tubes; only $17 \%$ of flowers on one plant at population 1 (of $n=12$ flowers per treatment) had pollen tubes in the autogamy treatment (fig. 4A). At both populations, the number of pollen tubes produced by the outcross treatment was greater than for the autogamy treatment (population 1: $q=$ 3.56, $\mathrm{df}=3, P<0.005$; population $2: q=4.13$, $\mathrm{df}=3$, 

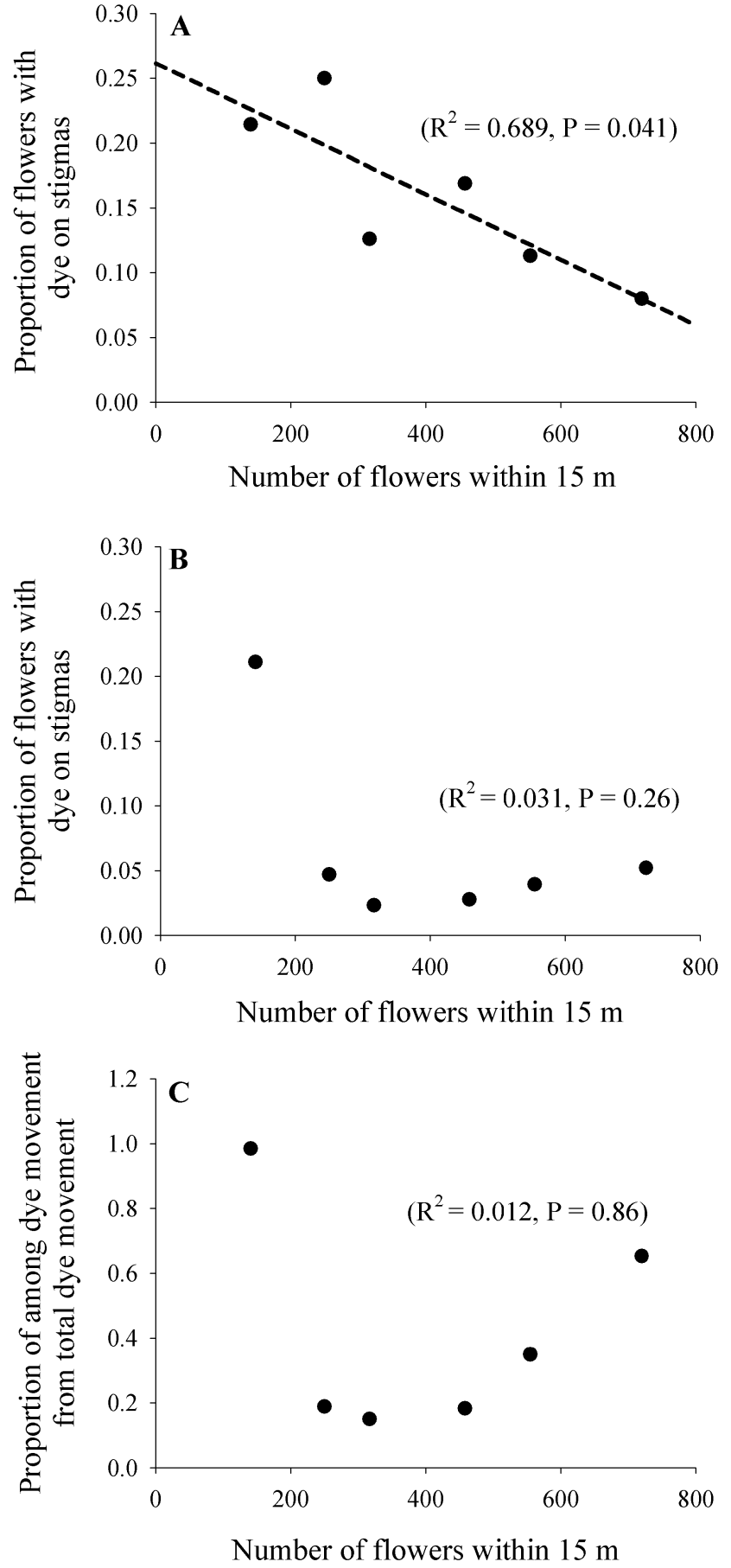

Fig. 3 Linear regression of the proportion of $(A)$ within-plant dye movements, $(B)$ among-plant dye movements, and $(C)$ among plantdye movements from the total dye movements, against the total flower density within six local environments of $15 \mathrm{~m}$. Proportions are based on the number of flowers that received a pollinator visit to the total undyed flowers available on the plant. Confirmation of a pollinator visit was based on the presence of fluorescent dye on the stigma of receptive flowers that were not from the dye source branch.
$P<0.001)$. In contrast to the autogamy treatment, the open treatment produced high variation among plants, with the number of pollen tubes ranging from $0 \%$ to $75 \%$ at population 1 and from $0 \%$ to $17 \%$ at population 2 (of $n=12$ ). The number of pollen tubes produced by the open treatment was greater than the number produced by autogamy at population $1(q=3.56, \mathrm{df}=3, P<0.02)$ but not at population 2 $(q=1.4, P>0.05)$. The number of pollen tubes produced by the open treatment ( $n=4$ of 60 flowers) was significantly less than for the outcross treatments at population $2(n=12$ of 60 flowers) $(q=2.69, \mathrm{df}=3, P<0.05)$; however, no significant difference was found between open treatment $(n=$ 20 of 60 flowers) and the outcross ( $n=17$ of 60 flowers) at population 1 ( $q=0.49, P>0.05$ ) (fig. 4 ).

Our observations of the morphology of the pollen tubes provided further evidence that $P$. bargoensis is more likely to set seeds after outcross pollination. None of the pollen tubes from the self ( 0 of 16$)$ or autogamy treatments ( 0 of 2) had continuous pollen tubes. This contrasted with the open and outcross treatments for which three of 22 and six of 29, respectively, had flowers with longer unfragmented pollen tubes that extended one-half to three-fourths the length of the style. The difference between the proportion of unfragmented pollen tubes in the self and outcross treatments was not statistically significant (Fisher's exact test, $P=0.074)$.

\section{Discussion}

\section{Pollinator Abundance and Plant Density}

Pollinator visitation to the flowers of Persoonia bargoensis was dominated by the introduced honeybee (Apis mellifera), to a greater extent than is indicated in reports of other Persoonia species (Bernhardt and Weston 1996; Wallace et al. 2002). However, the mean frequencies of pollinator visits per plant of all pollinator species together are similar to those described in previous studies (Wallace et al. 2002; Rymer et al. 2005). In our study, both plant size and local density of $P$. bargoensis affected the abundance of the main pollinator (Apis mellifera), but there was considerable variation between populations. In one population, mean pollinator visitation to an individual $P$. bargoensis increased as the local density and plant size increased, but in the second population where overall pollinator numbers were a quarter the number in the other population and plant density was much higher, this relationship was very weak.

Within the first population, pollinators are likely to be responding to the greater floral rewards found on larger plants and within denser local environments, which are more efficient to exploit and therefore more attractive to pollinators (Heinrich 1979; Pyke 1984). The results presented here are similar to those shown in experimental arrays for local plant density (Kunin 1993, 1997b; Karron et al. 1995; Mustajarvi et al. 2001) and plant size (Thomson 1988: Klinkhamer et al. 1989), but the effects are generally stronger.

Highly variable and weak density-dependent effects on pollinator behavior are not uncommon to natural population studies (Schmitt 1983; Bosch and Waser 1999; Bosch and Waser 2001). Replicated experiments in different seasons and 


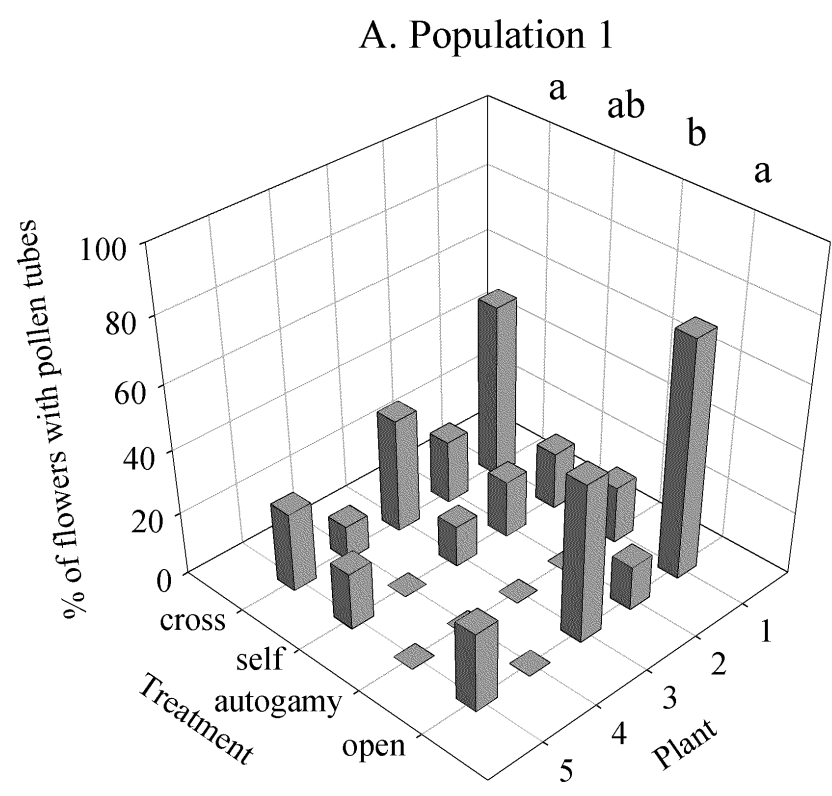

B. Population 2

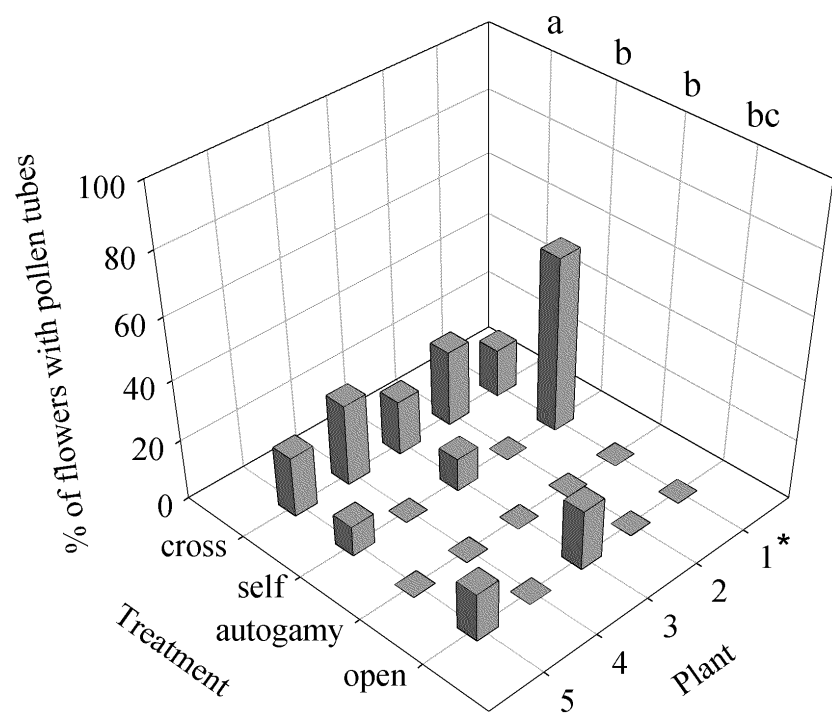

Fig. 4 Relative success of outcrossed (cross) and selfed (self) hand pollinations, bagged and not pollinated test for mechanical autogamy (autogamy), and open/unbagged pollination treatments (open) for five Persoonia bargoensis individuals at $(A)$ population 1 and $(B)$ population 2. Success for each treatment is based on the percentage of flowers that had any pollen tube growth along the style $(n=12$ flowers per treatment). Treatments with the same letter above indicate no significant difference (Tukey test: $P>0.05$ ). Asterisk indicates outlier plant that was excluded from the analysis.

different populations of the same species have shown that pollinator visitation generally decreases with local plant density (Bosch and Waser 2001), where previous studies had not (Bosch and Waser 1999). Since there was no spatial autocorrelation among individual plants in our study, the lack of density effects at the second population is likely to be the result of the lower number of total pollinators within the popu- lation, which is likely to influence visitation rates (Talavera et al. 2001). This could result from the significantly smaller plants at the second population, which would have attracted fewer overall pollinators since this population would have been less efficient to exploit by pollinators. Alternatively, the scale of local density that pollinators respond to could be in the range of 20 or fewer plants, adding to the weak relationship because the second population was much denser and had fewer plants representing the lower end of the density scale.

\section{Pollinator Foraging Patterns}

The behavior of pollinators and their foraging patterns were sensitive to the local flowering density of $P$. bargoensis, with pollinators making more within-plant movements at low local density. In our study, pollinators are likely to be less disposed to cross between plants when the local environment has a lower density of flowers, because it would be more efficient to forage more flowers within a plant before moving the greater distances to the next plant. Our findings are similar to those described for direct observation studies of pollinators in experimental arrays (Morris et al. 1994; Karron et al. 1995; Cresswell 1997; Mustajarvi et al. 2001) and natural populations (Ghazoul et al. 1998). However, fluorescent dye experiments have shown no density effect on pollinator movements from variation in pollinator types between density stands (Talavera et al. 2001).

Surprisingly, in our study, among-plant pollinator movements did not increase with local flower density, while there was a statistically significant relationship with within-plant movements. This pattern could be the result of two factors. First, it could be that the local flowering density influences pollinator activity within a plant, but once moving away, pollinators tended to move greater distances to plants out of the boundary of the surveyed local environment. Second, because honeybees are known as generalist pollinators, competition with other flowering species at the second population could also have reduced interplant movements.

\section{Preferred Mating System}

Our experimental pollinations revealed that low proportions of $P$. bargoensis flowers have pollen tubes, that there is no mechanical autogamy (indicating that pollinators are required for seed production), and that the species is self-compatible. There is evidence of a preference for outcross pollen in $P$. bargoensis, because there were higher numbers of pollen tubes in the outcross than the self treatment in one population. Furthermore, pollen tubes from the outcross treatment showed few signs of aberrant development (Goldblatt et al. 2004), being more continuous with few callose plugs (Kearns and Inouye 1993) compared with the self treatment. This result matches the findings of Jefferies and Belcher (1974) for self-incompatible apple trees.

Many authors have used the assessment of pollen tube growth and development as a surrogate for the assessment of successful pollination in a range of species, including apples (Jefferies and Belcher 1974) and other Proteaceae (Carthew 1993; Krauss 1994). Importantly, Krauss (1994) found that measurement of pollen tube growth was strongly correlated 
with later seed set in Persoonia mollis (Krauss 1994). Further quantification of the extent of outcross pollen preference in $P$. bargoensis would be difficult without following the pollination process through to at least seed set, which was not possible in our study.

Some of our results for pollen tube growth are similar to findings in other Persoonia species. Krauss (1994), for example, found that self pollen was inhibited within the style, with no pollen tubes of selfed flowers reaching the ovule. Autogamy was also the weakest performer of the treatments for Persoonia rigida (Trueman and Wallace 1999), but in contrast to our study, there was some pollen tube penetration into the ovule for autogamy and selfing treatments. Pollen tube penetration into the ovaries in P. bargoensis was very low for both the outcross and naturally pollinated flowers (less than $10 \%$ of pollen tubes) compared with about $50 \%$ in $P$. rigida (Trueman and Wallace 1999) and P. mollis (Krauss 1994). The low levels of ovule penetration observed in our study could be caused by extremely low rates of fertilization in the rare $P$. bargoensis, slower rates of pollen tube growth in this species than in others, or other factors, such as resource limitation, that are intrinsic to the sites.

In our study, the one plant that had a large number of selfed pollen tubes suggests variation in self-compatibility within populations of $P$. bargoensis. This has been described in studies of other Australian woodland shrubs (e.g., Young and Brown 1996).

The reduced success of the open-pollination treatment compared with hand pollination with outcross pollen at population 2 and the large variation among trees in the open treatment in the first population indicate variability in pollinator abundance, movements, and effectiveness. This could result from pollinator limitation for trees that are at lower densities (Kunin 1997a), substantial self pollen loads from a high proportion of within-plant pollinator movements (Ghazoul et al. 1998), or ineffective pollen transfer to the stigma by the introduced honeybees (Bernhardt and Weston 1996; Butz Huryn 1997), which have effectively replaced native bee foraging on $P$. bargoensis. Similar results with open treatments resulting in lower pollination than outcross hand pollinations have been reported in a number of Persoonia species (Krauss 1994; Rymer et al. 2005).

\section{Impact of Local Density}

Our results have illustrated the complexity of working with natural populations where interactions among plant size, local density, and variation in pollinator activity between populations can make generalizations difficult in regard to pollinator behavioral response to plant density. For one of the P. bargoensis populations, our results support the hypothesis that plants at low local densities may suffer reductions in pollination abundance. In addition, there may be an increase in self pollen loads and geitonogamous pollinations, since the fluorescent dyes showed that pollinators visited more flowers per plant when foraging within low local density. The mass-flowering strategy of P. bargoensis may also be maladaptive to pollinators such as the honeybee if having a great abundance of flowers open at one time reduces the pollinators' need to move between plants to forage, also increasing self pollen loads (Kenrick et al. 1987). These possibilities, taken together with the variable pollination rates (open treatment) and low pollination rates in the absence of pollinators (mechanical autogamy treatment), imply that the observed pollinator behavior may reduce seed production for plants at low local density. Furthermore, since P. bargoensis may have a preference for outcross pollen, the increase in within-plant pollinator movements may disrupt the pollination type because of dilution of outcross pollen and interference of self pollen loads on stigmas (Snow et al. 1996), which may negatively affect female fitness components by reducing seed set.

\section{Acknowledgments}

We thank David McKenna and Paul Rymer for their assistance in the field. This study was supported by an Australian Research Council grant to D. J. Ayre and R. J. Whelan and by the Institute for Conservation Biology, Wollongong University. This is publication 261 from the Ecology and Genetic Group of the University of Wollongong.

\section{Literature Cited}

Bernhardt P, PH Weston 1996 The pollination ecology of Persoonia (Proteaceae) in eastern Australia. Telopea 6:775-804.

Bosch M, N Waser 1999 Effects of local density on pollination and reproduction in Delphinium nuttallianum and Aconitum columbianum (Ranunculaceae). Am J Bot 86:871-879.

2001 Experimental manipulation of plant density and its effect on pollination and reproduction of two confamilial montane herbs. Oecologia 126:76-83.

Butz Huryn VM 1997 Ecological impacts of the introduced honeybees. Q Rev Biol 72:275-297.

Carthew SM 1993 Patterns of flowering and fruit production in a natural population of Banksia spinulosa. Aust J Bot 41:465-480.

Charlesworth D, B Charlesworth 1987 Inbreeding depression and its evolutionary consequences. Annu Rev Ecol Syst 18:237-268.

Cresswell JE 1997 Spatial heterogeneity, pollinator behaviour and pollinator-mediated geneflow: bumblebee movements in variously aggregated rows of oil-seed rape. Oikos 78:546-556.
Cresswell JE, AP Bassom, SA Bell, SJ Collins, TB Kelly 1995 Predicted pollen dispersal by honey-bees and three species of bumble-bees foraging on oil-seed rape: a comparison of three models. Funct Ecol 9:829-841.

de Jong TJ, NM Waser, PGL Klinkhamer 1993 Geitonogamy: the neglected side of selfing. Trends Ecol Evol 8:321-325.

Eguiarte LE, A Burquez, J Rodriguez, M Martinez-Ramos, J Sarukhan, D Pinero 1993 Direct and indirect estimates of neighbourhood and effective population size in a tropical palm, Astrocaryum mexicanum. Evolution 41:75-87.

Fenster CB 1991 Gene flow in Chamaecrista fasciculata (Leguminosae). I. Gene dispersal. Evolution 45:398-409.

Ghazoul J, KA Liston, TJB Boyle 1998 Disturbance-induced densitydependent seed set in Shorea siamensis (Dipterocarpaceae), a tropical forest tree. J Ecol 86:462-473.

Goldblatt P, P Bernhardt, P Vogan, JC Manning 2004 Pollution by fungus gnats (Diptera: Myceptophilidae) and self-recognition 
sites in Tolmiea menziesii (Saxifragaceae). Plant Syst Evol 244:55-67.

Goldingay RL, SM Carthew, RJ Whelan 1991 The importance of non-flying mammals in pollination. Oikos 61:79-87.

Goverde M, K Schweizer, B Baur, A Erhardt 2002 Small-scale habitat fragmentation effects on pollinator behaviour: experimental evidence from the bumblebee Bombus veteranus on calcareous grasslands. Biol Conserv 104:293-299.

Heinrich B 1979 Resource heterogeneity and patterns of movement in foraging bumblebees. Oecologia 48:235-245.

Jefferies CJ, AR Belcher 1974 A fluorescent brightener used for pollen tube identification in vivo. Stain Technol 49:199-202.

Jennersten O, SG Nilsson 1993 Insect flower visitation frequency and seed set in relation to patch size of Viscaria vulgaris (Caryophyllaceae). Oikos 68:283-292.

Karron JD, NN Thumser, R Tucker, AJ Hessenauer 1995 The influence of population density on outcrossing rates in Mimulus ringens. Heredity 75:175-180.

Kearns CA, DW Inouye 1993 Techniques for pollination biologists. University Press of Colorado, Boulder.

Kenrick J, P Bernhardt, R Marginson, G Beresford, RB Knox, I Baker, HG Baker 1987 Pollination-related characteristics in the mimosoid legume Acacia terminalis (Leguminosae). Plant Syst Evol 157: 49-62.

Klinkhamer PGL, TJ de Jong, GL de Bryun 1989 Plant size and pollinator visitation in Cynoglossum officinale. Oikos 54:201-204.

Krauss SL 1994 Restricted gene flow within the morphologically complex species Persoonia mollis (Proteaceae): contrasting evidence from the mating system and pollen dispersal. Heredity 73 : 142-154.

2000 Patterns of mating in Persoonia mollis (Proteaceae) revealed by an analysis of paternity using AFLP: implications for conservation. Aust J Bot 48:349-356.

Kunin WE 1993 Sex and the single mustard: population density and pollinator behaviour effects on seed-set. Ecology 74:2145-2160.

1997a Population biology and rarity: on the complexity of density dependence in insect-plant interactions. Pages 150-169 in WE Kunin, KJ Gaston, eds. The biology of rarity. Chapman \& Hall, New York.

1997b Population size and density effects in pollination: pollinator foraging and plant reproductive success in experimental arrays of Brassica kaber. J Ecol 85:225-234.

Martin FW 1959 Staining and observing pollen tubes in the style by means of fluorescence. Staining Technol 34:125-128.

Morris WF, PM Kareiva, PL Raymer 1994 Do barren zones and pollen traps reduce gene escape from transgenic crops? Ecol Appl 4: 157-165.

Mustajarvi K, P Siikamaki, S Rytkonenm, A Lammi 2001 Conse- quences of plant population size and density for plant-pollinator interactions and plant performance. J Ecol 89:80-87.

Pyke GH 1984 Optimal foraging theory: a critical review. Annu Rev Ecol Syst 15:523-575.

Richardson MBG, DJ Ayre, RJ Whelan 2000 Pollinator behaviour, mate choice and the realised mating systems of Grevillea mucronulata and Grevillea sphacelata. Aust J Bot 48:357-366.

Rymer PD, RJ Whelan, DJ Ayre, PH Weston, KG Russel 2005 Reproductive success and pollinator effectiveness differ in common and rare Persoonia species (Proteaceae). Biol Conserv 123:521-532.

Schmitt J 1983 Flowering plant density and pollinator visitation in Senecio. Oecologia 60:97-102.

Sih A, MS Baltus 1987 Patch size, pollinator behaviour, and pollinator limitation in catnip. Ecology 68:1670-1690.

Snow AA, TP Spira, R Simpson, RA Klips 1996 The ecology of geitonogamous pollination. Pages 191-216 in DG Lloyd, SC Barrett, eds. Floral biology. Chapman \& Hall, New York.

Talavera S, F Bastida, PL Oriz, M Arista 2001 Pollinator attendance and reproductive success in Citus libanotis L. (Cistaceae). Int J Plant Sci 162:343-352.

Thomson JD 1981 Spatial and temporal components of resource assessment by flower-feeding insects. J Anim Ecol 50:49-59.

1988 Effects of variation in inflorescence size and floral rewards on the visitation rates of traplining pollinators of Aralia hispida. Evol Ecol 2:65-76.

Threatened Species Conservation Act 1995 Threatened Species Conservation Act. NSW Government Information Service, Sydney.

Trueman SJ, HM Wallace 1999 Pollination and resource constraints on fruit set and fruit size of Persoonia rigida (Proteaceae). Ann Bot $83: 145-155$.

Van Treuren R, HJ Bijlsma, HJ Ouborg, W Van Delden 1993 The effects of population size and plant density on outcrossing rates in locally endangered Salvia pratensis. Evolution 47:1094-1104.

Wallace HM, GV Maynard, ST Trueman 2002 Insect flower visitors, foraging behaviour and their effectiveness as pollinators of Persoonia virgata R. Br. (Proteaceae). Aust J Entomol 41:55-59.

Waser NM, MV Price 1982 A comparison of pollen and fluorescent dye carry-over by natural pollinators of Ipomopsis aggregata (Polemoniaceae). Ecology 63:1168-1172.

Weston P, L Johnson 1991 Taxonomic changes in Persoonia (Proteaceae) in New South Wales. Telopea 4:269-306.

Young AG, AHD Brown 1996 Comparative population genetic structure of the rare woodland shrub Davesia suaveolens and its common congener D. mimosoides. Conserv Biol 10:1220-1228.

Zar JH 1984 Biostatistical analysis. 2nd ed. Prentice Hall, Upper Saddle River, NJ.

Zimmerman M 1981 Optimal foraging, plant density, and the marginal value theorem. Oecologia 49:148-153. 